\title{
Multi-Objective Metaheuristic Algorithm for Optimal Distributed Generator Placement and Profit Analysis
}

\author{
M. S. Jayasree ${ }^{1}$ - P. Sreejaya ${ }^{1}$ - G. R. Bindu ${ }^{1}$ \\ Received: 12 February 2019 / Accepted: 26 June 2019 / Published online: 13 July 2019 \\ (C) Springer Nature Singapore Pte Ltd. 2019
}

\begin{abstract}
The drastic growth in power demand and the high capital investment for infrastructure developments, power system utilities are forced to concentrate on improving the reliability and efficiency by integrating Distributed Generators(DG) to the existing grid. The integration of DG to grid faces many challenges. This paper presents the implementation of an algorithm based on multiobjective function for optimal placement of Distributed Generation(DG), which is one among the major challenges in DG integration. Optimal placement and sizing of Distributed Generator (DG), is done with the objective of loss minimization and maximization of loading capability without affecting voltage stability of the system. Flower Pollination Algorithm (FPA), which is a metaheuristic algorithm is used to solve this problem, since this algorithm is based on updating tuning parameters to obtain the most effective solution. The major expenditure in DG integration, as installation costs, operational cost and maintenance cost are taken into consideration and a cost based analysis is also carried out in this work to check the feasibility of optimum placement and sizing in a DG interconnected system. The benefits due to DG placement at optimum location with suitable size are the loss reduction and cost reduction. The performance of the proposed algorithm is tested on standard IEEE 33 bus and IEEE 69 bus systems. The effectiveness of the proposed algorithm is also tested on a 301 bus distribution system of Kerala State Electricity Board (KSEB). The test results are compared with other metaheuristic methods like Discrete Artificial Bee Colony algorithm (DABC) and Particle Swam Optimization (PSO) algorithm.
\end{abstract}

Keywords Distributed Generation · Optimal Placement · Flower Pollination Algorithm · Loadability Index

\section{Introduction}

In an attempt to improve the infrastructure to meet the ever increasing demand of power and operate power system economically, there is a need to implement Distributed Generators (DGs) in the existing system. The power utilization and power production are done at the distribution side in DG interconnected power system. As DGs are supplying power from renewable energy resources, to get the maximum benefits from

\section{S. Jayasree \\ msjaya@cet.ac.in \\ P. Sreejaya \\ sreejaya@ieee.org \\ G. R. Bindu \\ bgr100@gmail.com}

1 Department of Electrical Engineering, College of Engineering Trivandrum, Thiruvananthapuram, India
DG installation optimal handling of these resources are essential. The optimal DG placement problem is done by many researchers with the objective of loss minimization, voltage profile improvement and to maintain the stability. Higher losses cause breaking of thermal limits and voltage limits in the conductor material. In distribution system more emphasis is given to improve the maximum loadability limit rather than thermal limit.

One among the challenges in DG placement is the determination of suitable location and size of DG. Most of literature discusses this problem with loss minimization techniques [1, 2]. Another DG sitting and sizing method using Genetic Algorithm is discussed in [3]. Voltage stability improvement by placing DG is proposed in [4] and voltage stability and thermal limits to improve the loadability of the system is discussed in [5]. The loadability maximization method using continuation power flow is detailed in [6] and the maximum saving approach due to capacitor placement in [7]. The optimum DG placement algorithm proposed with maximization of system loadability is also considered in [8]. 
The discussed techniques of minimization of loss and improving voltage stability can be solved with many techniques such as analytical method like Linear Programming (LP) and heuristic methods like Genetic Algorithm (GA), Simulated Annealing (SA) and Particle Swam Optimization (PSA). Metaheuristic approaches based on analytical method are faster and easy to implement but its drawback is the difficulty in solving non-convex problems. The difficulties in previous algorithms and the nonconvexity are solved in this method [9]. But the disadvantage is that the problem concentrates only on loss minimization.

Optimal DG placement Problem solved in $[10,11]$ discuss the problem as a single objective one by Flower Pollination Algorithm. The proposed method discussed in this paper views the problem as a multi-objective $[12,23]$ one to minimize the losses with DG interconnection along with system loadability maximization. To attain this Flower Pollination Algorithm (FPA), which is based on the pollination process in the flowers is used [21]. It is proved that this algorithm is better in convergence compared to genetic algorithm and particle swarm optimization since it updates tuning parameters to obtain the most effective solution.

Most of the research in the area of DG interconnection to an existing grid mainly concentrates on the minimization of losses [22]. However the related profit maximization is not addressed. This paper also discusses a cost based analysis on DG interconnected systems. The analysis is done by considering generation, operating, investment and maintenance costs including the inflation rate and interest rate for a period of 10 years [13]. After the placement of DG, the energy purchase from utility can be reduced, and benefits due to loss minimization can be taken in to account.

The organization of the paper is as follows: In section II, the effect of DG on improving voltage stability and loadability is explained by the formulation of the problem as a multiobjective one which minimizes the losses. In section III, the implementation of the proposed method of DG placement algorithms with test results and discussions explained. Section IV details the cost analysis and incurred profits in test systems. Section V concludes the works.

\section{Formulation of Problem}

\section{Objective Function}

The proposed method aims at placing DG at suitable location with suitable size with the objective of loss minimization and loading capability maximization. Hence the problem is framed as a multiobjective optimisation problem and fitness as in (1).

Minimize,

$f\left(P_{\text {loss },} \lambda_{\max }\right)=a\left(P_{\text {loss },}\right)+b\left(\lambda_{\max }\right)$ where, $P_{\text {loss }}$ is real power loss, $\lambda_{\text {max }}$ is maximum loadability limit $\mathrm{a}, \mathrm{b}$ are multiplication factors $[0,1]$, where $(\mathrm{a}+\mathrm{b})=1$.

The loadability $(\lambda)$ is the ability of the system to handle maximum load connected, without breaking the system operation [15]. Here the voltage at each bus is the operating constraint and line current limits are system constraints.

Real power loss is given by (2)

$P_{\text {loss }}=\sum_{i=1}^{N B} I_{i}^{2} R_{i}$

Reactive power loss is given by (3) as

$Q_{\text {loss }}=\sum_{i=1}^{N B} I_{i}^{2} X_{i}$

where, $I_{i}$ is current through the $i^{\text {th }}$ transmission line, $R_{i}$ is resistance in the $i^{\text {th }}$ transmission line, $X_{i}$ is reactance of the $i^{\text {th }}$ transmission line and NB is total number of branches.

Substituting for current in eqs. (2) and (3) the total real power loss and reactive power loss in the feeders of the given system are given by the (4) and (5).

Real power loss is given by

$P_{\text {loss }}=\sum_{i=0}^{N B} \frac{P_{i, j}^{2}+Q_{i . j}^{2}}{\left|V_{i}^{2}\right|} R_{i, j}$

Reactive power loss is given by

$Q_{\text {loss }}=\sum_{i=0}^{N B} \frac{P_{i, j}^{2}+Q_{i . j}^{2}}{\left|V_{i}^{2}\right|} X_{i, j}$

The objective function is formulated by considering the total losses in the system by connecting DG at optimum locations.

$\mathrm{P}_{\text {loss }}$ in (1) becomes $\mathrm{P}_{\text {DGloss }}$ in (6) when DG is integrated into the existing system.

The actual loss [9] in the DG interconnected system is calculated as (6)

$P_{D G L o s s}=\sum_{i=0}^{n-1} \frac{\left(P_{i . j}-P_{D G . j}\right)^{2}+\left(Q_{i . j}-Q_{D G . j}\right)^{2}}{\left|V_{i}\right|^{2}} R_{i . j}$

where, $\mathrm{P}_{\mathrm{DG}, \mathrm{j}}, \mathrm{Q}_{\mathrm{DG}}$ are the capacity of the DG unit or active and reactive power injections at bus $\mathrm{j}$.

\section{Constraints}

The inequality constraints are given by voltage constraint, line current limits and size of DG given by (7), (8) and (9).

Voltage constraint is that the voltage in each bus should be maintained within limits

$V_{i \min } \leq V_{i} \leq V_{i \max }$ 
Size of the DG should also be maintained within the given limits

$S_{D G \min } \leq S_{D G} \leq S_{D G \max }$

Current limits must be less than the maximum fault current rating of switch gear.

$I_{\min }^{i} \leq I_{\text {Limit }}^{i} \leq I_{\max }^{i}$

where $\mathrm{I}_{\text {limit }}$ is $\mathrm{i}^{\text {th }}$ branch current limit.

Position of DG should be such that $\mathrm{DG}_{\mathrm{pos}} \neq 1,1$ is the slack bus.

The other constraints for the calculation of fitness function are the variations in load to maximize the loadability [8], as in Fig. 1. The actual power load and reactive power load are increased in steps of $1 \%$ and new values are calculated as in (10) and (11)

$P_{\text {load }}=P_{0} \times \lambda$

$Q_{\text {load }}=Q_{0} \times \lambda$

where, $\mathrm{P}_{0}$ and $\mathrm{Q}_{0}$ are the initial actual power load and reactive power load respectively and loading factor is $\lambda$.

The kilo Volt Ampere Margin to Maximum Loadability (KMML) [15] is calculated in (12)

$K M M L=S_{\text {Load }}\left(\lambda_{\max }-1\right)$

where, $\mathrm{S}_{\text {Load }}$ is base MVA load and is given by (13)

$S_{\text {Load }}=\sqrt{\sum_{i=2}^{N B} P_{i}^{2}+\sum_{i=2}^{N B} Q_{i}^{2}}$

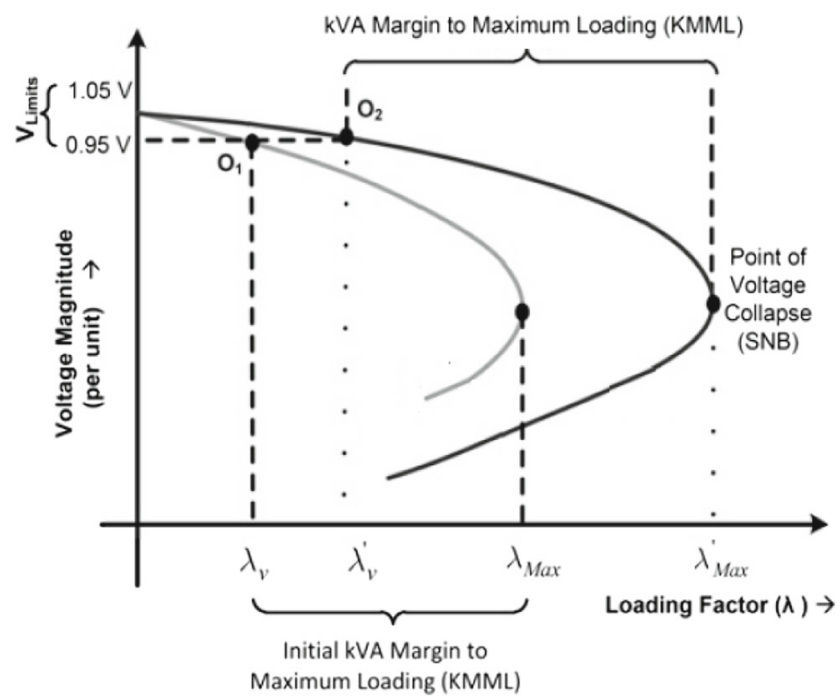

Fig. 1 Variation of voltage with loading Factor [15]

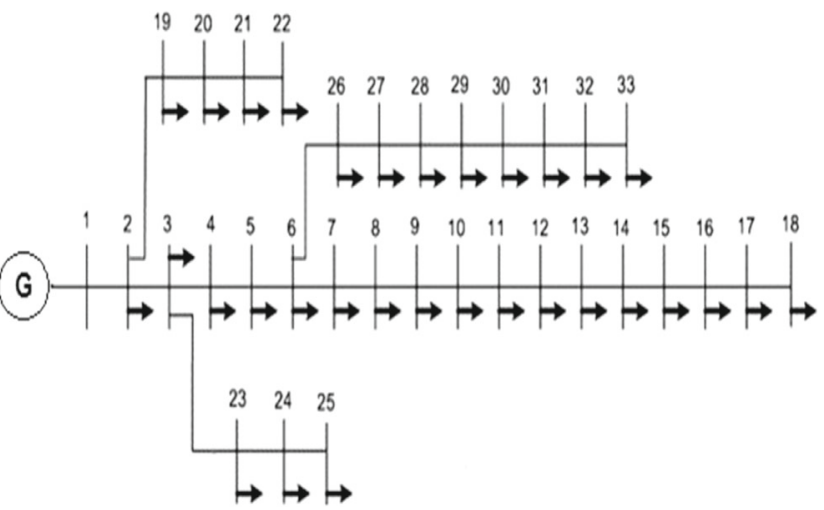

Fig. 2 33-Bus distribution test system

\section{Identification of Maximum Loadability}

The lambda max is the factor of load which can be added to the power system without violating the voltage limit. It is identified using the Maximum Loadability Index (MLI) [8]. Following are the steps involved,

Step 1: Read the bus data, line data, and accuracy for power flow.

Step 2: Set the lambda values for 1 to 10 in steps of 0.01 factor. Calculate the new real power load and reactive power load as in (14) and (15).

$P_{L}=P_{\text {Lold }}+P_{\text {Lold }} \times \lambda$

$Q_{L}=Q_{\text {Lold }}+Q_{L}$ old $\times \lambda$

Here and $Q_{L}$ are the new real and reactive loads applied, $P_{\text {Lold }}$ and $Q_{\text {Lold }}$ are the old real and reactive loads in the power system.

Step 3: Perform the power flow using new load data. Identify minimum voltage, power loss and Maximum Loadability Index (MLI) value (calculated as per equation in [16]), which must be greater than 1 if the bus system is not weak.

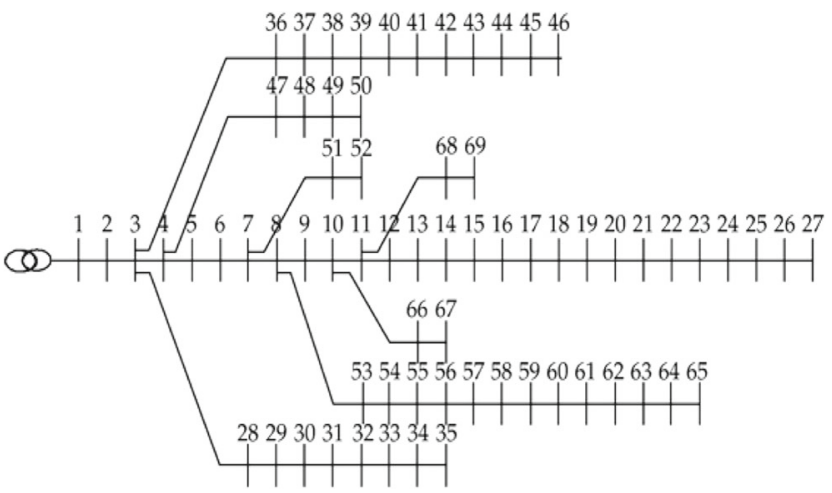

Fig. 3 IEEE 69 Bus distribution test system 


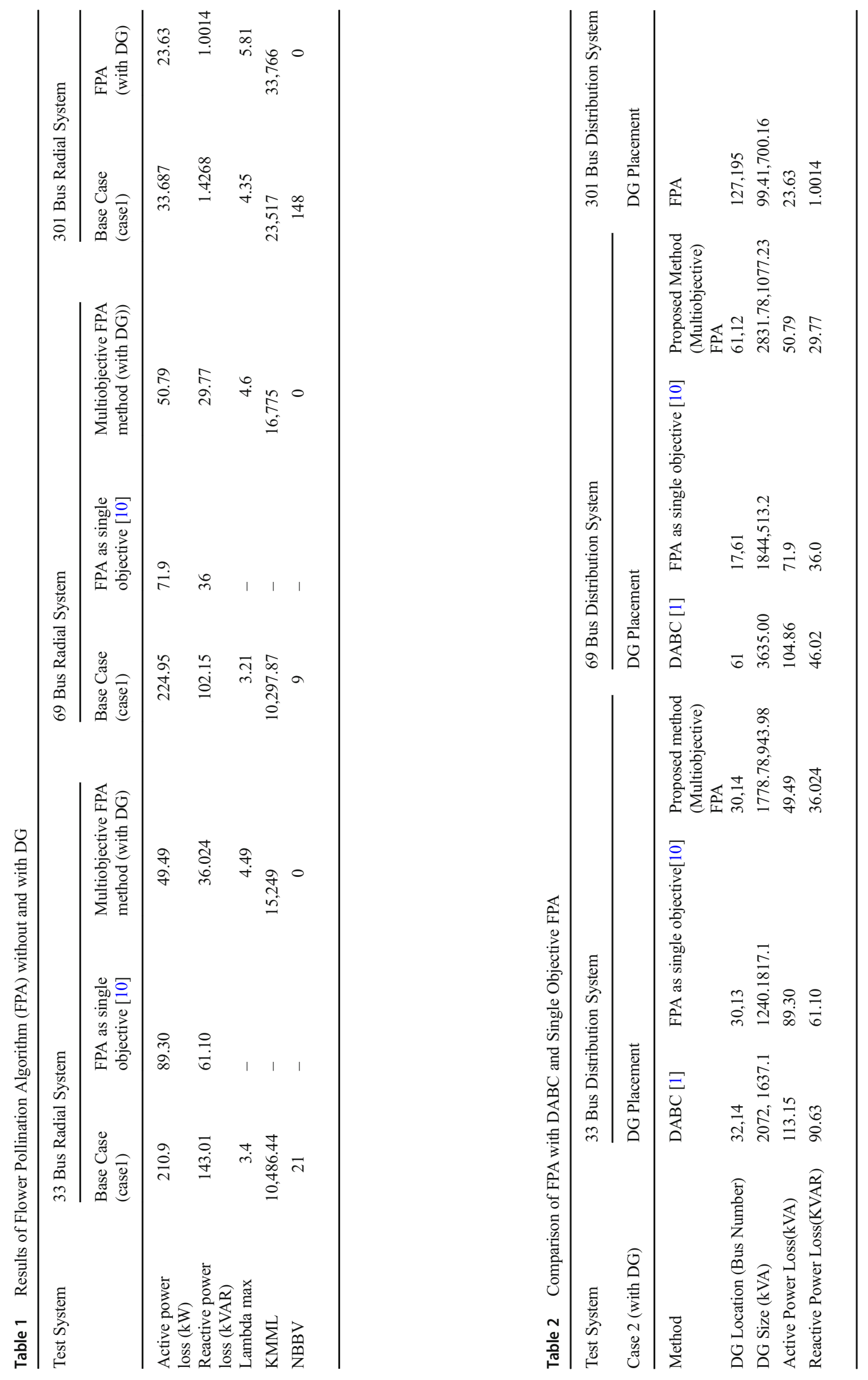


Step 4: Increment the value and go to step 2 if the (MLI) is greater than 1 and convergence is achieved from power flow.

Step 5: Else save the values of power loss, voltages and $\lambda$ as $\lambda_{\max }$ value. Evaluate Number of Buses Violating the Voltage constraint (NBVV) [16].

Step 6: Plot the graph between Lamda max values and minimum voltage calculated in step 3 .

Step 7: Display the final results.

\section{Size of Distribution Generator}

In the proposed method the DG is supplying actual power and reactive power to the connected bus. The range of DG sizes considered between 0.1 MVA to 5 MVA and two DGs are placed as in [8] for comparative study. The power factor assumed is 0.95 for all the systems. Real power and reactive power given by (16) and (17),

$P_{D G}=S_{D G} \times \cos \varphi$

$Q_{D G}=\sqrt{S_{D G}^{2}-P_{D G}^{2}}$

where, $P_{D G}$ is actual power of DG, $Q_{D G}$ is reactive power of $\mathrm{DG}$ and $\mathrm{S}_{\mathrm{DG}}$ rating of $\mathrm{DG}$.

\section{Flower Pollination Algorithm}

The Flower Pollination Algorithm (FPA) is formulated by Xin-She Yang in 2013. [14]. The different steps of algorithm given below.
Step 1: Initialize the population number (n), total iteration, search probability and dimensions. (Here 4 dimensions in the format of [DG location- $1 D G$ size-1 DG location-2 DG size-2] which has 4 columns of population. Here population size is taken as 40 . So, the number of flowers considered here is 40 and the total of [40X4] is the population considered, total iteration is 100 and switch probability is 0.8 .

Step 2: Evaluate the fitness function (1) and find the initial global best flower $\left(\mathrm{g}_{*}\right)$.

Step 3: While the maximum iteration is not reached perform the global pollination operation using $X_{i}^{t+1}=X_{i}^{t}+$ $L\left(g_{*}-X_{i}^{t}\right)$ if the probability value is less than any random value between $[0,1]$. Here ' $i$ ' is the population number and ' $\mathrm{t}$ ' is iteration number. $\mathrm{X}$ is the 4 dimension population matrix and $\mathrm{L}$ is the levy's distribution.

Step 4: If the random value is greater than the probability value then perform the local pollination using $X_{i}^{t+1}$ $=X_{i}^{t}+\in\left(X_{j}^{t}-X_{k}^{t}\right)$ here $X_{\mathrm{j}}$ and $\mathrm{X}_{\mathrm{k}}$ are the pollens of different flowers of the same type. is the uniform distribution between $[0,1]$.

Step 5: Calculate the new fitness values from (1) using new pollens from the step 3 or step 4 .

Step 6: if the new fitness is less than the old then modify them in the population

Step 7: find the global best $\mathrm{g}_{*}$

Step 8: iteration count incremented and go to step 3.

Step 9: If maximum iterations reached, display the results.
Fig. 4 Voltage in pu at each bus (33 bus distribution system)

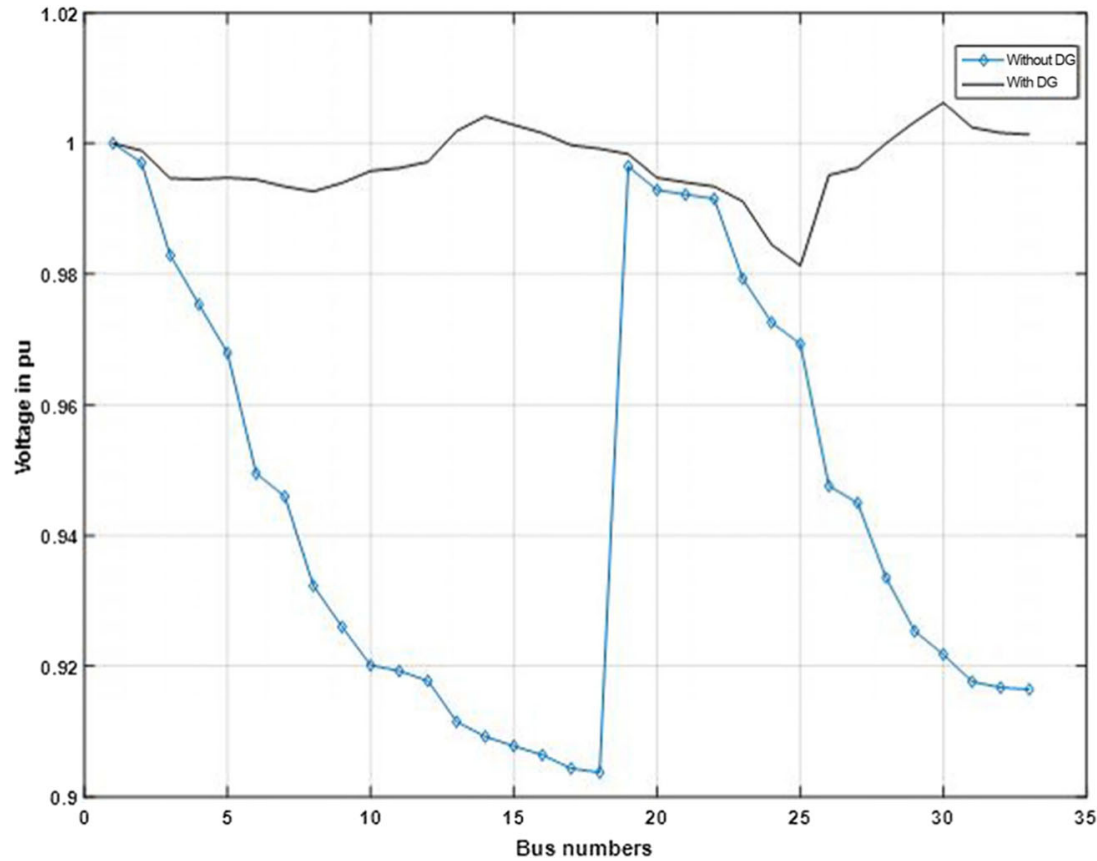


Fig. 5 Lambda max versus minimum voltage in pu (33 bus distribution system)

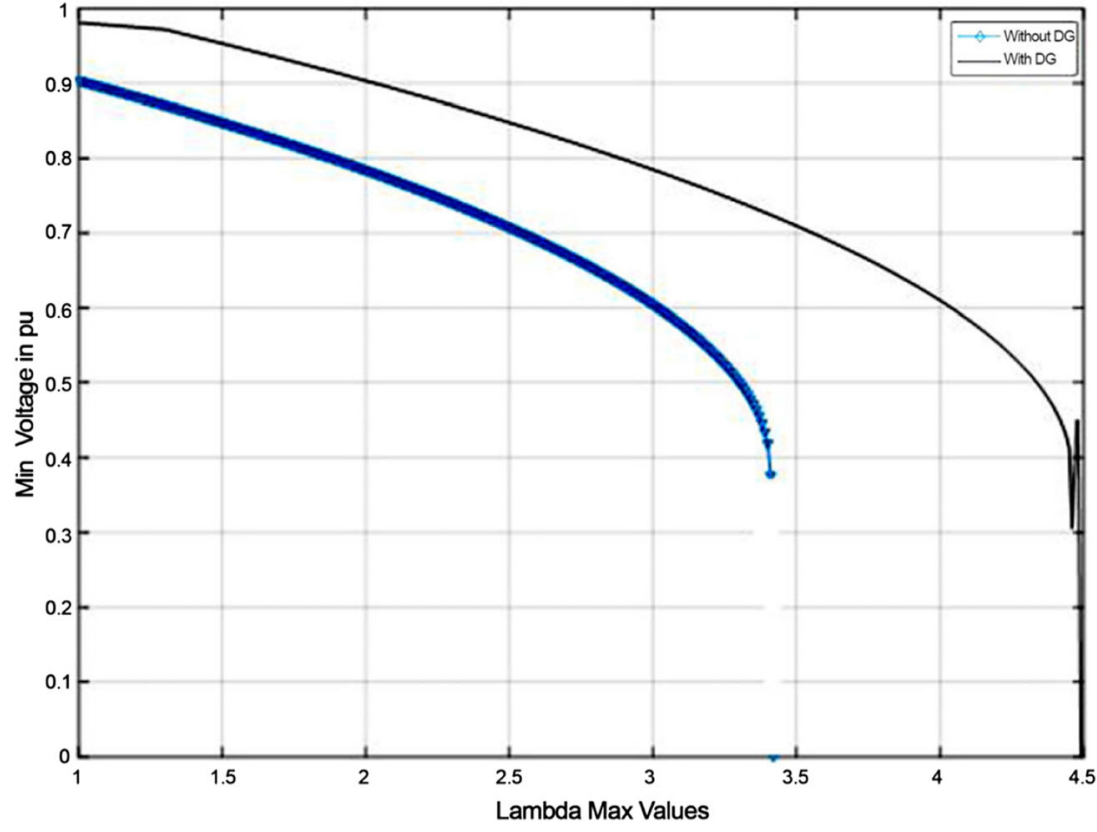

\section{Implementation of FPA in Test Systems}

\section{Test systems}

The proposed algorithm is applied on 3 phase system of $12.66 \mathrm{kV}$ standard IEEE 33 bus a distribution system and IEEE 69 bus distribution systems [15]. The type of DG chosen is a Type 2 system, injecting actual power and reactive power. The systems are assumed to be operating at a constant power factor of 0.95 . Figure 2. shows the line diagram of a 33 bus radial distribution test system consisting of 33 buses and 39 line segments with a base load of $4369.35 \mathrm{kVA}$. 69 bus system shown in Fig.3. has 76 line segments. The base case load is
4659.67kVA for this system and the results for both the systems are tabulated in Table 1 and Table 2.

\section{Real system (KSEB)}

The future demands of power system will be met mainly by integrating DGs. Since the major source of power in the state of Kerala is hydroelectric power plants and are also dependent on climatic conditions. As an initiative by Ministry of New and Renewable Energy Sources(MNRES), Kerala State Electricity Board (KSEB) has also started to promote consumers to install roof top solar panels and wind turbines. Hence a typical sample 301
Fig. 6 Voltage in pu at each bus (69-Radial bus system)

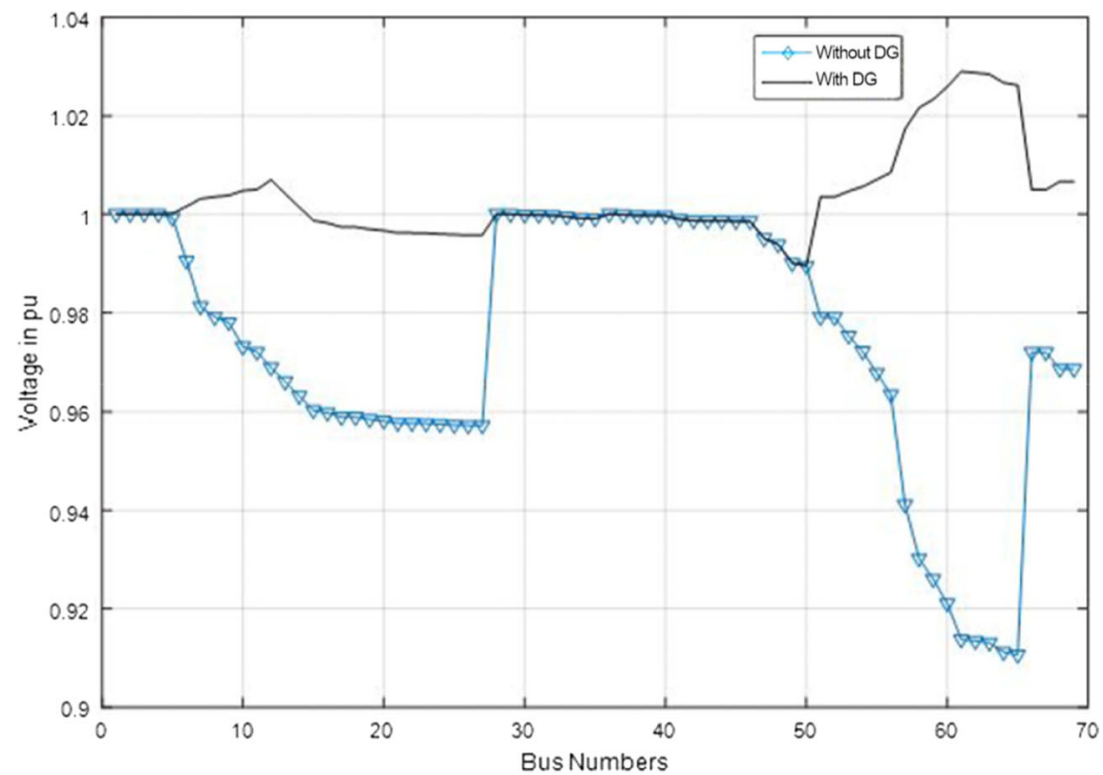


Fig. 7 Lambda max versus minimum voltage in pu (69Radial bus system)

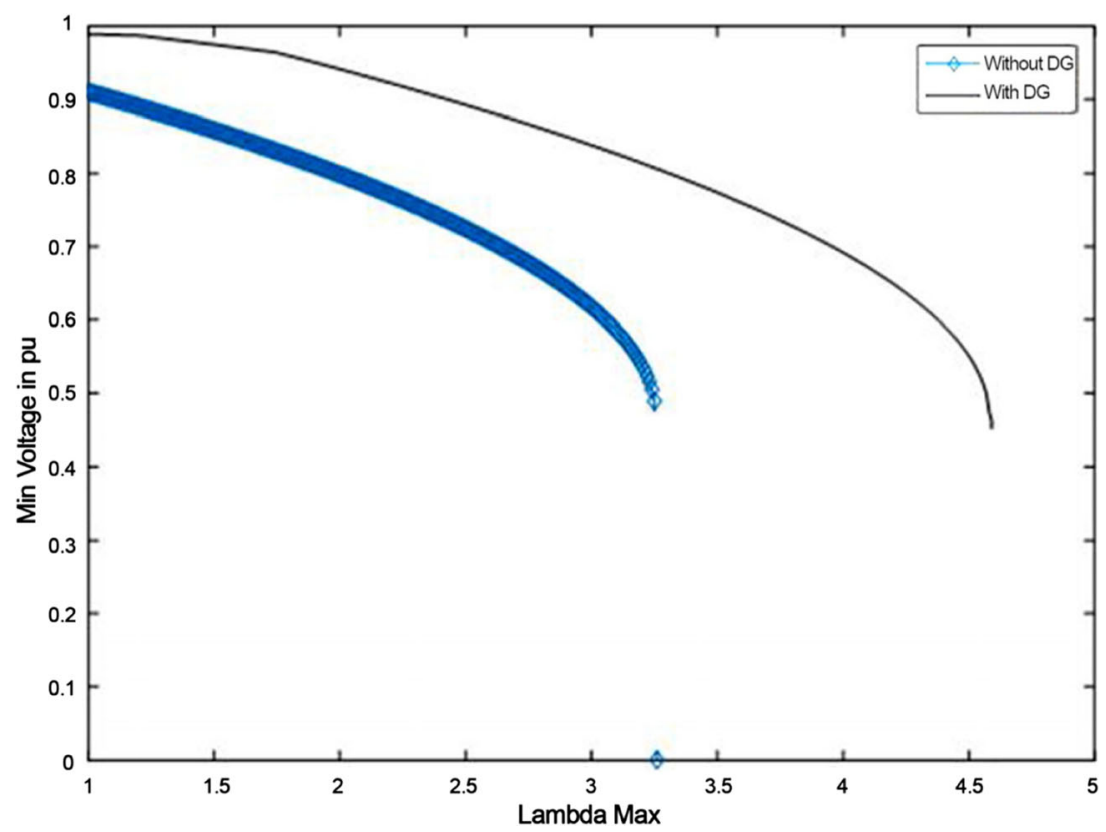

bus radial distribution feeder is considered for the validation of the proposed method. The system consists of $11 \mathrm{kV}$ feeders with base MVA of 100, with 301 buses and 302 lines. The base case load is $700.6 \mathrm{kVA}$. The results are tabulated in Table 1 and Table 2.

\section{Results and Discussion}

The algorithm is applied to different systems and the results without DG and with DG are shown in Table 1. There are significant improvement in loss reduction and maximum loadability with the integration of DGs. The results of the multiobjective FPA is compared with Discrete Artificial Bee Colony optimization (DABC) technique [8], Modified Flower Pollination Algorithm(MFPA) [10] and are tabulated in Table 2.

The result indicates that the proposed method utilizing FPA performs better. For sizing and placement of DG for 33-bus system, 2 DGs with rating of $5 \mathrm{MW}$ are connected to the system. The real power losses reduce from $113.15 \mathrm{~kW}$ [DABC], $89.30 \mathrm{~kW}$ [MFPA] to $49.49 \mathrm{~kW}$. Similarly reactive power also gets reduced from 90.63kVAR[DABC], 61.10Kvar [MFPA] to $36.024 \mathrm{kVAR}$ with proposed method.
Fig. 8 Voltage in pu at each bus (301-Radial bus system)

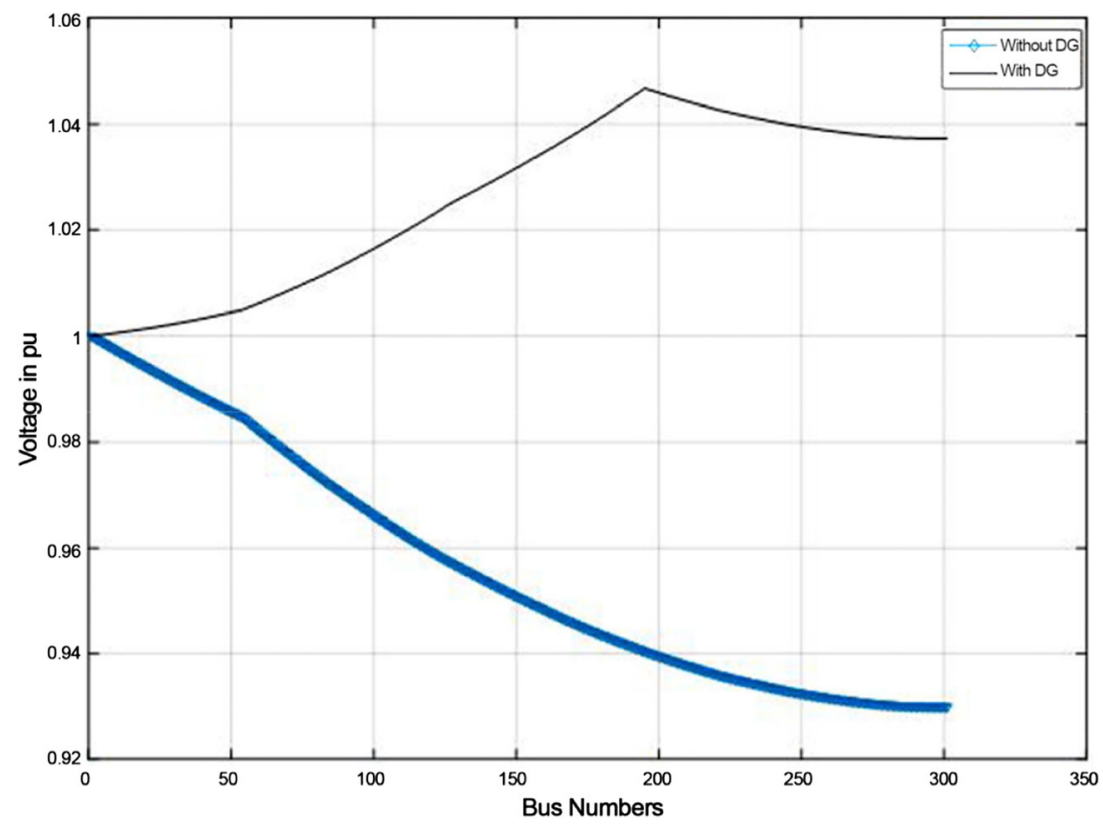


Fig. 9 Lambda max versus minimum voltage in pu (301Radial bus system)

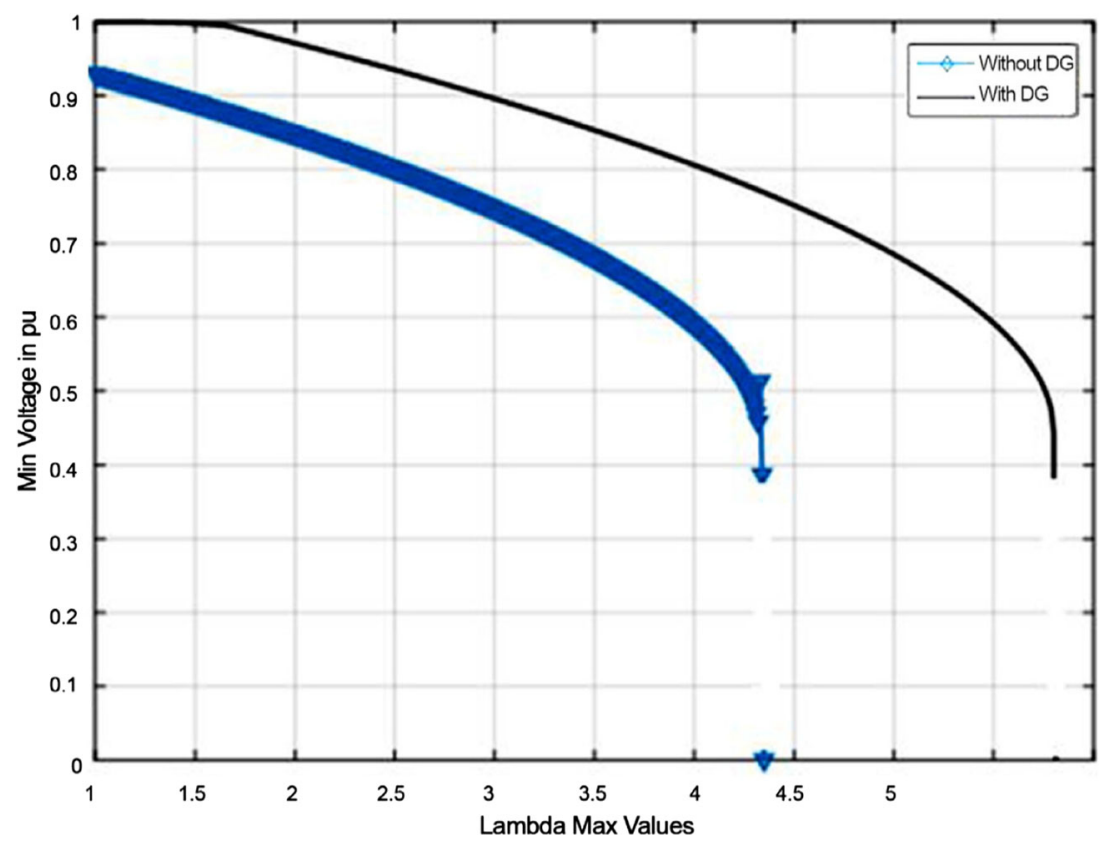

In case of 69-bus system two DGs are connected to the system with $5 \mathrm{MW}$ capacity. The generation from each DG are $2831.78 \mathrm{~kW}$ and $1077.23 \mathrm{~kW}$. The real power losses reduced from $104.86 \mathrm{~kW}$ [DABC], $71.9 \mathrm{~kW}$ [MFPA] to $50.79 \mathrm{~kW}$ and reactive power reduced from 46.02kVAR[DABC], $36.0 \mathrm{kVAR}$ [MFPA] to $29.77 \mathrm{kVAR}$. The DGs are placed at bus 61 and 12 there is considerable reduction in losses as shown in Table 2. The added advantage of the loss reduction in proposed method is that extra loads can be connected in the system, thus attaining the objective of load maximization.

Thus the optimal placement and sizing by considering losses and maximization of loadability limit is obtained in the proposed method.

Along with DG placement the voltage profile of the system is ploted for all the buses. The variation of minimum voltage with lambda maximum values are obtained for the minimum voltage bus. It is seen that the voltage profile got improved with the interconnection of distributed generators. Figure 4. and Fig. 6 shows the voltage profile graphs. The KMML value for 33 bus and 66 bus systems are drastically incresed in FPA compared to base case due the loss reduction.

The number of buses exceeding or Violating Voltage limits(NBVV) are 21 for 33 bus and 9 for 69 bus systems with no DG. The lodability margin improvement is shown in Fig.5 and Fig.7. Thus it is proved that the kilo Voltampere Margin to Maximum Loadability (KMML) also improved with interconnection of DGs in the distribution systems.

The results on real system data also proves that the losses in the system reduce due to the interconnection of DGs. The voltage profile is better and is shown in Fig.8 and Lodability plot is shown in Fig.9. The proposed method performs well in loss minimization, optimal DG selection and loadability margin.

Table 3 Cost Analysis of Proposed Method [17-19]

\begin{tabular}{|c|c|c|c|c|c|c|c|}
\hline \multirow{2}{*}{$\begin{array}{l}\text { Test System } \\
\text { Method }\end{array}$} & \multicolumn{3}{|c|}{33 Bus Radial system } & \multicolumn{3}{|c|}{ 69Bus Radial system } & \multirow{2}{*}{$\begin{array}{l}301 \text { Bus Radial system } \\
\text { FPA }\end{array}$} \\
\hline & $\begin{array}{l}\text { DABC } \\
{[8]}\end{array}$ & $\begin{array}{l}\text { PSO } \\
{[13]}\end{array}$ & FPA & $\begin{array}{l}\text { DABC } \\
{[1]}\end{array}$ & $\begin{array}{l}\text { PSO } \\
{[20]}\end{array}$ & FPA & \\
\hline Installation cost in INR(lacs) & 927.275 & 375 & 680.69 & 908.75 & 375 & 977.25 & 199.85 \\
\hline Operating cost in INR(lacs) & 6169.5 & 2490 & 4528.9 & 6046.2 & 2490 & 6502 & 1329.7 \\
\hline Maintenance cost in INR(lacs) & 1565.2 & 634 & 1149 & 1533.9. & 634 & 1649.5 & 337.42 \\
\hline Benefits of reduced loss in INR(lacs) & 325.52 & 435 & 537 & 399.67 & 652 & 579.54 & 33.45 \\
\hline Benefit of DG in INR (lacs) & 12,339 & 4990 & 9057 & 12,092 & 4990 & 13,004 & 2659.4 \\
\hline Total profit in INR(lacs) & 4002.6 & 1937.94 & 3236.5 & 4003.3 & 2137.19 & 4454.8 & 825.89 \\
\hline
\end{tabular}




\section{Cost analysis}

\section{Major expenditure in DG installation}

The cost of installation, cost of operation and maintenance cost are the major expenditure involved while adding DGs in an existing system [13]. The mathematical modelling done by (18) to (21).

\section{Installation cost of DG (IC)}

The installation cost includes the expenditure for site investigation, construction, equipment monitoring and cost of DG as in (17)

$I C=\left(D G_{\text {size }}^{1}+D G_{\text {size }}^{2}\right) \times D G_{\text {cost }}^{I C}$

where, $\mathrm{DG}_{\text {size }}^{1}, \mathrm{DG}_{\text {size }}^{2}$ are optimal selected DG sizes in $\mathrm{MW}$ and $\mathrm{DG}^{\mathrm{IC}}$ cost is $\mathrm{DG}$ investment cost in INR.

\section{Operating cost of DG (OC)}

$O C=\left(D G_{\text {size }}^{1}+D G_{\text {size }}^{2}\right) \times D G_{\text {cost }}^{o c} \times O T \times \beta$

where, $D G_{\text {cost }}^{O C}$ is DG operating cost in INR and OT is total time of operation in hours

$\beta=\sum\left(\frac{1+I F}{1+I R}\right)^{t}$

where, $\beta$ is present worth factor, IF is inflation rate, IR is interest rate and ' $\mathrm{t}$ ' is the duration in years as 1 to 10 .

\section{Maintenance cost (MC)}

This cost comes as yearly cost including the mechanical and electrical cost of renovation and given in (21)

$$
\begin{aligned}
M C= & \left(D G_{\text {size }}^{1}+D G_{\text {size }}^{2}\right) \times D G_{\text {cost }}^{I C} \times I C \times \beta \times M C_{\text {ratio }} \\
& +10,000
\end{aligned}
$$

where $\mathrm{MC}_{\text {ratio }}$ is ratio of the maintenance cost to investment cost and is taken as $20 \%$ of DG investment cost per year.

\section{Benefit analysis}

With DG installation the power taken from the grid is lesser and more power is injected to the grid. The additional benefit due to reduction in loss is given in (22).

Benefit due to loss minimization $\left(\mathrm{B}_{\mathrm{L}}\right)$

$$
B_{L}=\left(P_{\text {loss }}^{b}-P_{\text {loss }}^{D G}\right) * E P_{G} * O T * \beta
$$

where, $\mathrm{EP}_{\mathrm{G}}$ is the price of power purchased from grid, $P_{\text {lossb }}$ is base case real power loss in $\mathrm{kW}$ and $P_{\text {loss }}^{D G}$ is real power loss with DG placement in $\mathrm{kW}$.

Benefits due to not using grid power

$B_{g}=\left(D G_{\text {size }}^{1}-D G_{\text {size }}^{2}\right) \times E P_{G} \times O T \times \beta$

Profit $=\left(B_{L}+B_{g}\right)-(I C+O C+M C)$

(23) gives the profit which is the difference between the total cost and benefit.

Profit based feasibility of DG placement for long term planning with cost analysis is carried out. Analysis is done for 10 years period and the total operating hours of the DGs are calculated as $7884 \mathrm{~h}$. DG units used are assumed as non operating for a period of $10 \%$ of the total operating period. The rate of interest is $12.5 \%$ and inflation rate is $9 \%$ for this case. The total purchase cost of the power from grid is taken as $5 / \mathrm{kWh}$ INR [13]. The cost data are given as

Cost of installation with DG, ICi $=25 \times 10^{6} / \mathrm{MW}$, Operational cost, with DG, OCi $=2.5 \times 10^{3} / \mathrm{MWh}$

Maintenance cost with $\mathrm{DG}, \mathrm{MC}_{\mathrm{DG}}=(10,000+20 \%$ of DG installation cost)/year

Rate of Interest IR $=12.5 \%$

Rate of Inflation rate, IF $=9 \%$

Planning period, $n=10$ years.

Table 3 shows the results of cost analysis of proposed DG placement method compared to $[8,13]$. Though the cost incured in the proposed method seems to be high compared to PSO, this increase can be attributed to the fact that in the proposed method two DGs are used while the PSO method uses one DG. This reflects in the installation cost, operating cost and mainteance cost naturally. In comparison with DABC method which also uses two DGs the proposed method clearly shows an improvement in the overall profit. In 69- bus system the total profit for the proposed method is higher than the DABC method and PSO method. It indicates that as the number of nodes increases, FPA method seems to be the most suitable one. The test results on 301-bus distribution system profit is calculated as 825.89 lacks INR for an operating period of 10 years.

\section{Conclusion}

The DG systems there optimal placement and sizing form a major area of research. This paper presents an optimal DG placement method for loss minimization along with maximization of system loadability using Flower Pollination Algorithm. The application of this algorithm proved that there is a major reduction in power loss in the proposed systems. 
The loadability margin also improved with the integration of DGs in the existing system. The benefit of this method is that the existing infrastructure can be utilized by increasing the loadability rather than providing extra lines in the system, thereby improving the efficiency and reliability of the system. Further cost analysis with DG placement at optimum locations and with suitable size proves that the method is beneficial. The advantage is that the voltage stability limits are also maintained with no buses violating the constrained limits which show better power quality of system.

The comparison results show the superiority of the algorithm with existing metaheuristic algorithms. The validation of the algorithm in the real system proves that this method can be effectively applied in real DG interconnected distribution systems. For long term planning with DG, feasibility based on cost analysis gives better profit.

Acknowledgements The real system data for this work has been carried out on the data available from Kerala State Electricity Board (KSEB). Authors acknowledge the support given by the Planning section of KSEB for providing the data for the validation of this work.

\section{References}

1. Kalambe S, Agnihotri G (2014) Loss Minimization Techniques Used In Distribution Network: Bibliographical Survey. Renew Sust Energ Rev 29:184-200

2. Hedayati H, Nabaviniaki S, Akbarimajd A (2008) Method For Placement Of DG Units In Distribution Networks. IEEE Transactions on Power Delivery 23:1620-1628

3. Abou El-Ela AA, Allam SM, Shatla MM (2010) Maximal Optimal Benefits Of Distributed Generation Using Genetic Algorithms. Electr Power Syst Res 80:869-877

4. Ettehadi M, Ghasemi H, Vaez-Zadeh S (2013) Voltage StabilityBased DG Placement In Distribution Networks. IEEE Transactions on Power Delivery 28:171-178

5. Prada RB, Souza LJ (1998) Voltage Stability and Thermal Limit: Constraints on the Maximum Loading of Electrical Energy Distribution feeders. IEE Proceedings-Generation,Transmission and Distribution 145:573-577

6. Milano F (2010) Continuation Power Flow Analysis, Power Syst. Model. Scripting, 103-130

7. Khodr HM, Olsina FG, Jesus PMDO-D et al (2008) Maximum Savings Approach For Location and Sizing of Capacitors in Distribution Systems. Electr Power Syst Res 78:1192-1203

8. Aman MM et al, (2016) "Optimum Tie Switches Allocation And DG Placement Based On Maximization Of System Loadability Using Discrete Artificial Bee Colony Algorithm", IET Generation, Transmission \& Distribution

9. Sanjay R, Jayabharathi T, Reghunathan T, Ramesh V and Mithulanathan N (2017) Optimal Allocation Of Distributed Generation Using Hybrid Grey Wolf Optimizer IEEE Access 5
10. Oda ES, Abdelsalam AA (2017) Optimal DGs Allocation In Distribution Networks Using Modified Flower Pollination Algorithm 2017, Nineteenth International Middle East Power Systems Conference (MEPCON), Menoufia University, Egypt

11. Kumar Sudabattula S, Kowsalya M (2016) Flower Pollination Algorithm Based Optimal Placement Of Solar Based Distributed Generators In Distribution System. International Journal Of Renewable Energy Research, 6, 4

12. Dian Budhi Santoso, Sarjiya, Fredi Prima Sakti, Optimal Sizing and Placement of Wind-Based Distributed Generation to Minimize Losses Using Flower Pollination Algorithm JTERA - Journal Technology Rekayasa, Vol. 3, No. 2, December 2018, Hal. 167176

13. Kansala S, Tyagib B, Kumarb V (2015) Cost-Benefit Analysis For Optimal Distributed Generation Placement In Distribution Systems, International Journal Of Ambient Energy

14. Yang X-S (2012) Flower Pollination Algorithm for Global Optimization, Unconventional Computation and Natural Computation 2012. Lect Notes Comput Sci 7445:240-249

15. Aman MM, Jasmon GB, Bakar AHA et al (2014) A New Approach Optimum Simultaneous Multi-DG Distributed Generation Units Placement And Sizing Based On Maximization Of System Loadability Using HPSO (Hybrid Particle Swarm Optimization) Algorithm. Energy 66:202-215

16. Venkatesh B, Rajan R, Gooi H (2004) Optimal Reconfiguration Of Radial Distribution System To Maximum Loadability. IEEE trans Power Syst 19:260-266

17. El-Khattam W, Hegazy YG, Salama MMA (2005) An Integrated Distributed Generation Optimization Model for Distribution System Planning. IEEE Trans Power Syst 20:1158-1165

18. Willis HL, Scott WG (2000) Distributed Power Generation Planning and Evaluation. Marcel Dekker, New York

19. Wills HL (2004) An Integrated Distributed Generation Optimization Model for Distribution System Planning. Power Distribution Planning. New York: IEEE Transactions on Power Systems, 20, 1158-1165

20. Zad BB, Hasanvand H, Lobry J, Vallee F (2015) Optimal Reactive Power Control of DGs for Voltage Regulation of MV Distribution Systems using Sensitivity Analysis Method and PSO Algorithm. Int J Electr Power energy Syst 68:52-60

21. Moradi MH, Zeinalzadeh A, Mohhammadi M, Abedini M (2014) An Efficient Hybrid Method For Solving The Optimal Sitting And Sizing Problem Of DG And Shunt Capacitor Banks Simultaneously Based On Imperialist Competitive Algorithm And Genetic Algorithm. Int J Electr Power Energy Syst 54:101-111

22. Thukaram D, Wijiekoon Banda H, Jerome J (1999) A Robust Three Phase Power Flow Algorithm For Radial Distribution System. Electr Power Syst Res 50:227-236

23. Kothari DP, Dhillon JS, Power System Optimization. PHI Learning Private Limited. NewDelhi

Publisher's Note Springer Nature remains neutral with regard to jurisdictional claims in published maps and institutional affiliations. 